\title{
A Procedure for Standardizing Individually Administered Tests, Normed by Age or Grade Level
}

\author{
William H. Angort \\ Educational Testing Service \\ Gary J. Robertson \\ American Culdance Service
}

This paper describes a method for standardizing in dividually administered tests, which, for practical reasons, are ordinarily normed on small samples. Typically, these samples yield irregular distributions at each age level, and irregular trends in means and standard deviations across age levels. To ameliorate this situation, a procedure is presented that uses the fitted progression of data across the age levels to develop a normalized aggregate distribution of all available cases, with appropriate corrections for the moments of the individual distributions. This aggregate distribution is used to represent the norms at every age level, after adjustment for differences in level and dispersion. The procedure produces norms with improved stability and comparability, and it yields a smooth, lawful progression of scores from one age to the next. To the extent that the samples of children at every age level represent the same cohort, except for differences in level and dispersion of scores associated with age changes, these data will closely approximate a set of longitudinal norms, but captured at one point in time.

One of the principal difficulties encountered in the standardization of individual tests of intelligence derives from the very fact that they are individual tests. Unlike group tests of intelligence, interest, personality, aptitude, or achievement, individual tests require a one-to-one type of administration: one test-giver to one test-taker. As a consequence, the statistical and monetary savings that

APPLIED PSYCHOLOGICAL MEASUREMENT

Vol. 11, No. 1, March 1987, pp. 33-46

(C) Copyright 1987 Applied Psychological Measurement Inc. 0146-6216/87/010033-14\$1.95 are associated with, and result from, the use of cluster sampling are usually unavailable to the developer of individual tests. Because the cost of each administration is so high, great reliance is placed on the integrity of each testing, and examinees chosen to constitute the standardization sample are selected with great care, each one sought out and identified, ideally, to fit the demands of a complex sampling frame. However, because of the inordinate cost of each testing, far smaller samples are used for norms for individual tests than for group tests. As a consequence, random errors and irregularities in the data are less likely to balance out and are therefore more frequent in the standardization of individual tests than in the standardization of group tests.

These problems are quite familiar both to those who develop and use individual tests. The manual for the 1937 revision of the Stanford-Binet (Terman \& Merrill, 1937, p. 40) reported an average sample size of only 204 per age for ages 2 through 14 in the standardization of the test, and an average sample size of 105 per age for ages 15 through 18 ; the manual for Form L-M of the 1972 edition of the Stanford-Binet (Thorndike, 1973, p. 56) reported using an average of about 190 cases per age for ages $2-5$, about 131 cases per age for ages $6-15$, and about 93 cases per age for ages 16-18; the McCarthy Scales of Children's Abilities (McCarthy, 1972, p. 18) reported using 102 cases at age $2 \frac{1}{2}$, an average of 205 cases at ages 3,4 , and 5 , and an average of 105 cases at ages $61 / 2,71 / 2$, 
and $81 / 2$; and the wiSC-R (Wechsler, 1974, p. 20) reported using 200 cases at every age from $61 / 2$ to $16 \frac{1}{2}$. With samples as small as these, however well they are selected and however well they are tested, there is a virtual certainty that the distributions at each age level will be highly irregular and that the pattern of distributional characteristics across age levels will be uneven. This is true even if the most sophisticated techniques of sampling are employed to ensure that the same type of cohort is sampled at every age level.

Despite such difficulties, test developers in the past have generally accepted the data as they have received them, perhaps smoothing the individual distributions-usually, without taking advantage of the availability of other data in the set-and, perhaps, also making minor adjustments in the progression of means across the ages. Typically, however, the test developer has exercised no further fundamental adjustments in the data other than to normalize the distributions at each age level and to set standard score, or "IQ," means and standard deviations equal.

The procedure described here differs from those used for other age-related (and grade-related) tests in that it attempts to borrow strength from the distributions of scores at all levels in developing the distribution of scores at each level, and calls on techniques to adjust for irregularities both within and between age levels. The procedure is identical in principle to that used to standardize the Kaufman Assessment Battery for Children (KABC; Kaufman \& Kaufman, 1983), but differs from it in matters of detail.

The procedure involves the following general steps:

1. Identification of an "anchor" age at or near the middle of the age range;

2. Conversion of the observed distributions at all age levels to the observed distribution at the anchor age;

3. Aggregation of all such converted distributions in terms of the distribution at the anchor age;

4. Passage of a fitted curve through the progression of the means of the several age-level distributions, and a second fitted curve through the progression of standard deviations;
5. Adjustment of the frequencies of the aggregate distribution to reflect the fitted mean and standard deviation at the anchor age;

6. Normalization (and smoothing) of the aggregate distribution, and the assignment of a standard-score mean and standard deviation which would apply at all age levels; and

7. The provision of a conversion between raw scores and standard scores at each age level.

Data from the Riddles Test, one of the 16 subtests of the KABC, are used below to illustrate the implementation of the procedure.

\section{Hoplementatenton}

The first step is to form a distribution of scores $(y)$ at each level (i) and to calculate the mean, $M_{y_{i}}$ and standard deviation, $s_{y_{i}}$, at each age level. Table 1 gives these distributions for the data of the KABC Riddles Test, the number of cases (100 at each age level), the mean, and the standard deviation at each age level. The "age levels" shown in Table 1 are actually code numbers for the different age ranges, as shown in Table 2.

The next several steps in the process call for the aggregation of all distributions, in this instance from Age Level 2 to Age Level 20, adjusted to reflect all the moments of the distribution at a selected age level (the anchor age), preferably near the middle of the age range (Age Level 11-ages 7-6 to $7-11$-in the KABC data). The method of adjustment and aggregation consists of the following steps:

1. The distribution at each of the age levels is "converted" by the equipercentille conversion method to the distribution at the anchor age defined above. In carrying out this procedure the general case is assumed, in which the shapes of the distributions at each age level differ from one another by more than would be expected by chance. Thus, in the conversion of any score distribution from one age group to another, and in the aggregation of distributions across age groups, area transformations (i.e., equipercentile equatings) are indicated; linear transformations, which do not change the shapes of the converted distributions, would not be sufficient. (Of course, in those instances where 


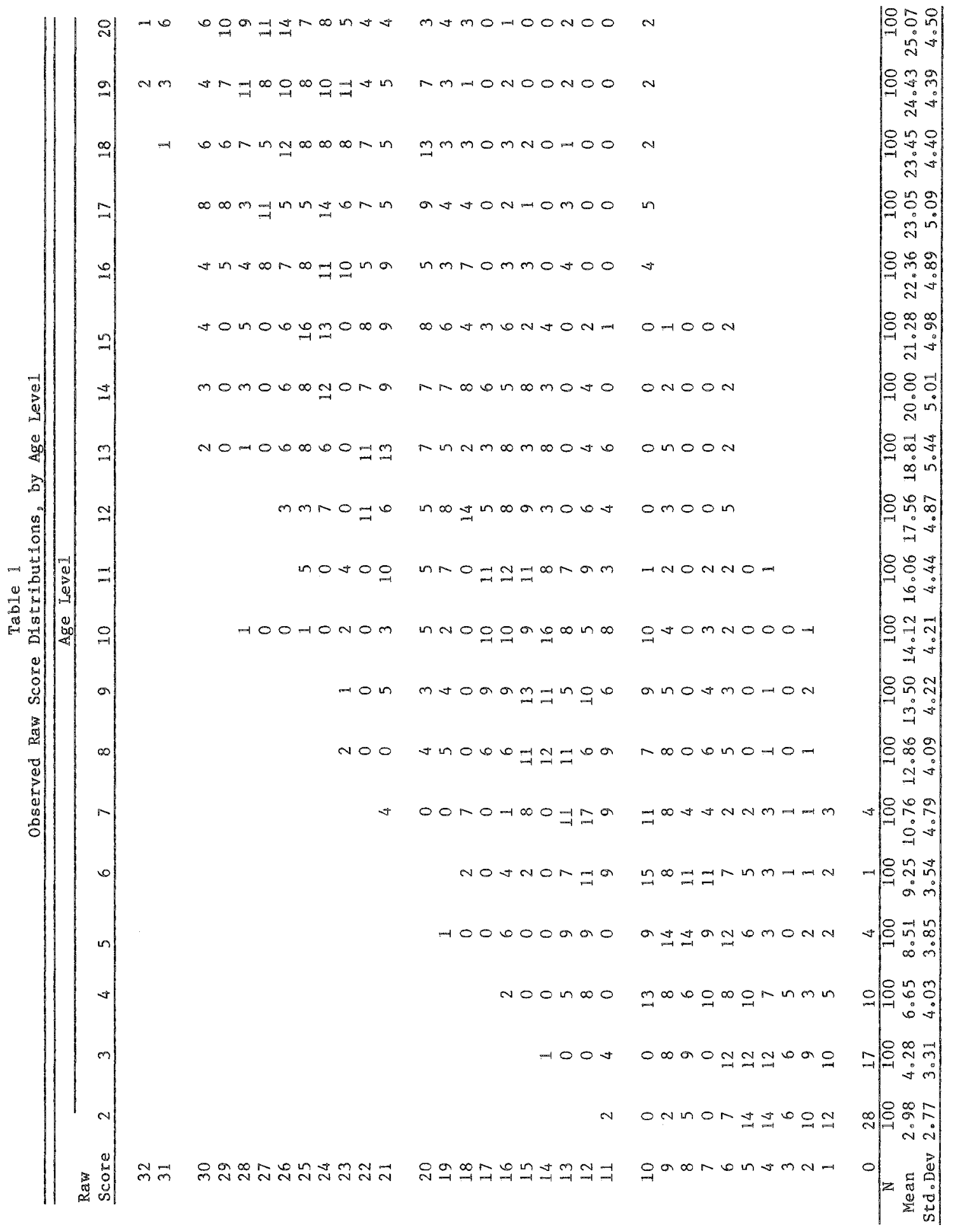

Downloaded from the Digital Conservancy at the University of Minnesota, http://purl.umn.edu/93227. May be reproduced with no cost by students and faculty for academic use. Non-academic reproduction requires payment of royalties through the Copyright Clearance Center, http://www.copyright.com/ 
Table 2

Code Numbers Corresponding to Age Ranges

\begin{tabular}{cccccc}
\hline $\begin{array}{l}\text { Code for } \\
\text { Age Leve1 }\end{array}$ & $\begin{array}{c}\text { Age Range } \\
\text { (Yrs. \& Mos) }\end{array}$ & $\begin{array}{c}\text { Code for } \\
\text { Age Level }\end{array}$ & $\begin{array}{c}\text { Age Range } \\
\text { (Yrs. \& Mos.) }\end{array}$ \\
\hline $2^{\text {a }}$ & $3-0$ to $3-5$ & $11^{\mathrm{b}}$ & $7-6$ to & $7-11$ \\
3 & $3-6$ to $3-11$ & 12 & $8-0$ to & $8-5$ \\
4 & $4-0$ to $4-5$ & 13 & $8-6$ to & $8-11$ \\
5 & $4-6$ to $4-11$ & 14 & $9-0$ to & $9-5$ \\
6 & $5-0$ to $5-5$ & 15 & $9-6$ to & $9-11$ \\
7 & $5-6$ to $5-11$ & 16 & $10-0$ to $10-5$ \\
8 & $6-0$ to $6-5$ & 17 & $10-6$ to $10-11$ \\
9 & $6-6$ to $6-11$ & 18 & $11-0$ to $11-5$ \\
10 & $7-0$ to $7-5$ & 19 & $11-6$ to & $11-11$ \\
& & & 20 & $12-0$ to & $12-5$ \\
\hline
\end{tabular}

athe Riddles Test was not administered at Age Level 1 $(2-6$ to $2-11)$.

bAnchor age leve1.

the distribution shapes may be considered to vary slightly and only by chance, linear transformations would ordinarily be sufficient.) The equipercentile equating carried out here is of the usual type, in which scores on two forms of a test are taken as equivalent if their percentile ranks in the same or equivalent groups are equal. Here, the test is actually the same; it is the groups that are different. The process calls for:

(a) plotting the ogives for the several age-level distributions, including the distribution at the anchor age;

(b) smoothing those ogives;

(c) reading the scores corresponding to, say, 30 different percentile ranks ranging from about 1 to about 99 on each of the several ogives;

(d) plotting the points on the distribution for the anchor age against the corresponding points on each of the other distributions; and

(e) smoothing the resulting plotted curves. (A description of the equipercentile equating method may be found in Angoff, 1984, pp. 7-101.)

2. The raw scores on each of the separate agegroup plots, corresponding to the boundary raw scores $(1.5,2.5,3.5,4.5$, etc.) at the anchor age, are read from the smoothed equipercentile curves.

3. The raw scores on each of the distributions that are "equivalent" to the boundary raw scores on the anchor age distribution (Step 2) are now used as the argument on each of the ogives that were plotted and smoothed in Step 1 to read the consequent percentile ranks. These percentile ranks are the percentages of cases at each age level falling below the equivalent anchor age scores $-.5, .5,1.5,2.5,3.5$, etc. Note that at any given anchor age score level, these percentile ranks should be very nearly the same across all age levels.

4. Each percentile rank column is decumulated to yield relative frequencies (summing to 100 in each column). A check on the reasonableness of the "equating" of the scores at each age level to the anchor age may be made by calculating, and comparing, the means (and other moments) of the several columns of relative frequencies. There should be very little variation among them. In the $\mathrm{KABC}$ data the raw score means ranged from a low of 15.95 to a high of 16.45 . The mean of the smoothed distribution at the anchor age was found to be 16.02 , differing only slightly from the original 
(observed) mean of 16.06 at that age level.

5. All smoothed equated relative frequencies developed in Step 4 are now aggregated, raw score by raw score, across age levels to yield a combined distribution of cases. As a check, it may be determined whether the mean and standard deviation (and all other moments) of the aggregate distribution are close to the corresponding statistics at the anchor age. In the $\mathrm{KABC}$ data, the mean of the aggregate distribution (of smoothed equated relative frequencies) was 16.03. The standard deviation was 4.45; the original standard deviation was 4.44 . The percentage of cases in the aggregate distribution falling below each score (read at score 1.5 , $2.5,3.5$, etc.) is now plotted on arithmetic probability paper and smoothed, as in Figure 1 . The following steps involve fitting second-degree equa- tions to the traces of means and standard deviations, across age levels.

Plots of the original raw scores means, $M_{y_{i}}$, and of the original raw score standard deviations, $\mathrm{s}_{y_{i}}$, are made against age level. (See Table 1 for the means and standard deviations for the KABC data.) As may be observed in Figure 2, the means fall very closely on a negatively accelerating curve, characteristic of intellectual growth curves observed for children. However, the standard deviations (Figure 3), which would ordinarily be expected to increase with age (at least in this age range), are seen to decline slightly with age in the $\mathrm{KABC}$ data following a rise up to age level 13 or thereabouts. In general, both plots may be smoothed by fitting a second-degree polynomial of the form $y=a+b x+c x^{2}$, where $x$ represents age level, $y$ represents the fitted mean (Figure 2) or standard

\section{Figure 1}

Ogive of Combined Distributions,

Aggregated in Terms of the Observed Distribution at the Anchor Age

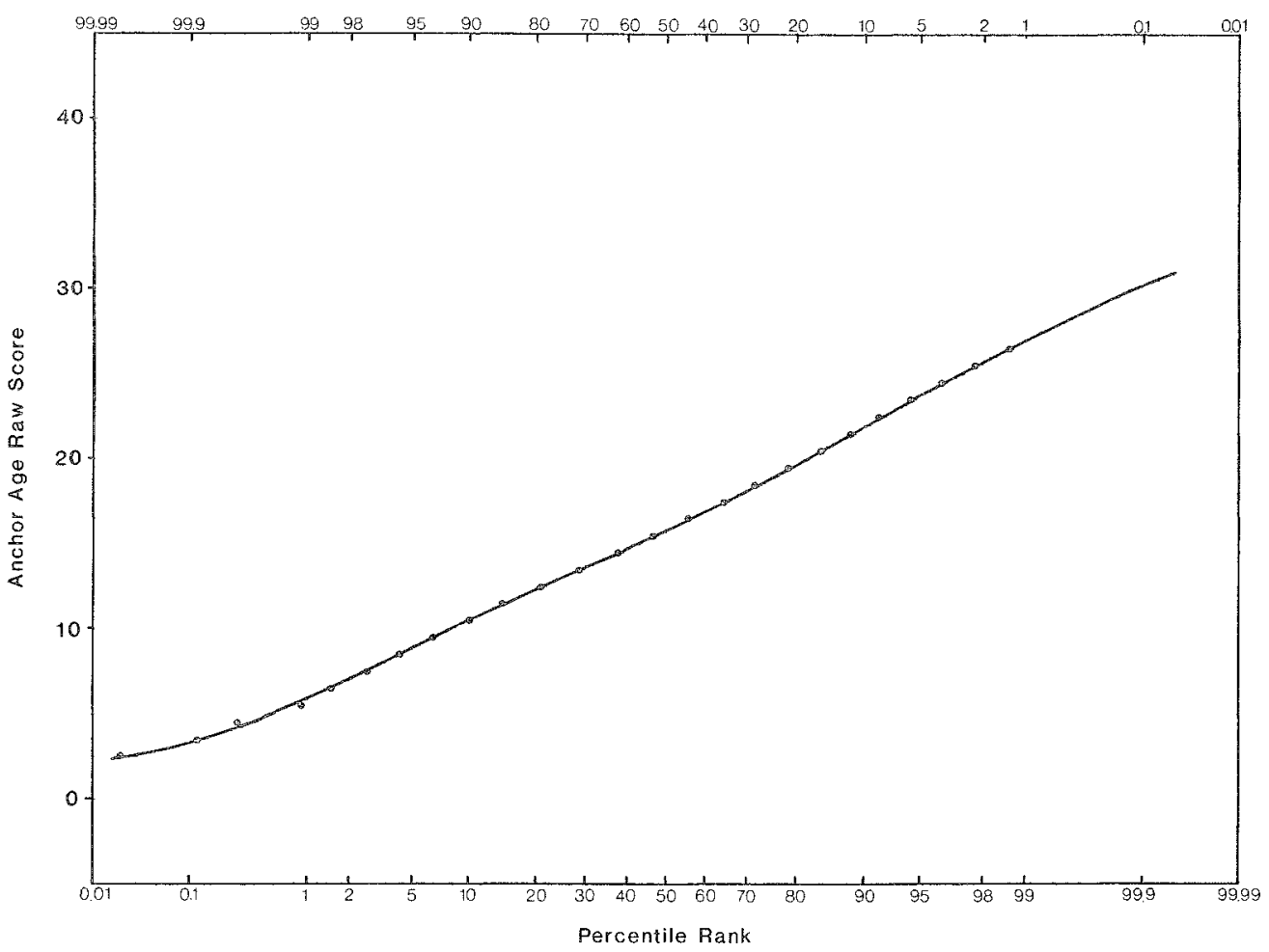

Downloaded from the Digital Conservancy at the University of Minnesota, http://purl.umn.edu/93227. May be reproduced with no cost by students and faculty for academic use. Non-academic reproduction requires payment of royalties through the Copyright Clearance Center, http://www.copyright.com/ 
Figure 2

Plot of Observed and Fitted Means, by Age Level

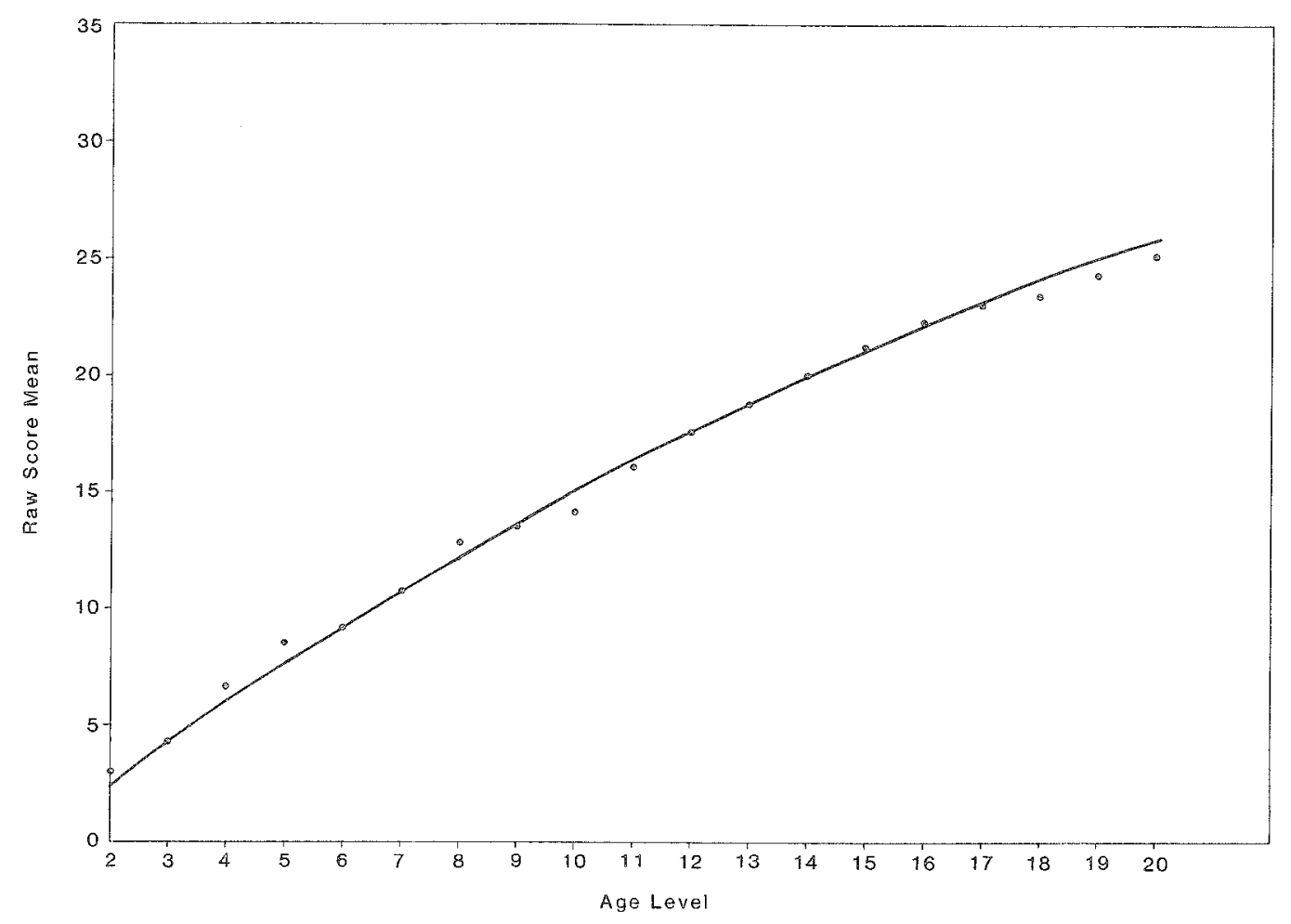

deviation (Figure 3) at each age level, and $a, b$, and $c$ are the parameters of the equation. The actual process of curve-fitting may be found in any one of several reference books (e.g., Peters \& Van Voorhis, 1940, pp. 429-431). In the KABC data the best-fitting second-degree equation through the means was found to be

$\mathrm{M}_{\bar{y}}=-1.19+1.89 x-.027 x^{2}$.

The corresponding equation for the curve through the standard deviations was

$\mathrm{s}_{\bar{y}}=2.29+.36 x-.13 x^{2}$.

Table 3 lists the fitted values of mean and standard deviation corresponding to each age level. (Because the parameters given in Equations 1 and 2 are rounded values, they will yield slightly different means and standard deviations from those given in Table 3.)

The next step calls for converting the aggregate distribution (developed above) from one with its own mean $\left(\mathbb{M}_{y_{a}}=16.03\right)$ and standard deviation $\left(s_{y_{a}}=4.45\right)$ to one with precisely the same shape, but with a mean equal to the fitted mean $\left(\mathrm{M}_{\hat{y}_{a}}=\right.$ 16.34) and fitted standard deviation $\left(s_{\hat{y}_{a}}=4.74\right)$ at the anchor age. For reasons of computational convenience, this conversion - which necessarily calls for a linear equation - is actually carried out in the opposite direction, yielding scores $\left(y_{a}\right)$ at the anchor age in the aggregate distribution which are equivalent to scores $\left(\tilde{y}_{a}\right)$ also taken at the anchor age, but possessing the fitted mean and standard deviation. The values of the parameters, $A_{a}$ (slope) and $B_{a}$ (intercept), of the conversion equation are calculated as follows:

$A_{a}=\mathrm{s}_{y_{a}} / \mathrm{s}_{\tilde{y} a}$,

$B_{a}=\mathbb{M}_{y_{a}}-A_{a} \mathbb{M}_{\tilde{\gamma} a}$,

obtained by rearranging the terms of the equation 
Figure 3

Plot of Observed and Fitted Standard Deviations, by Age Level

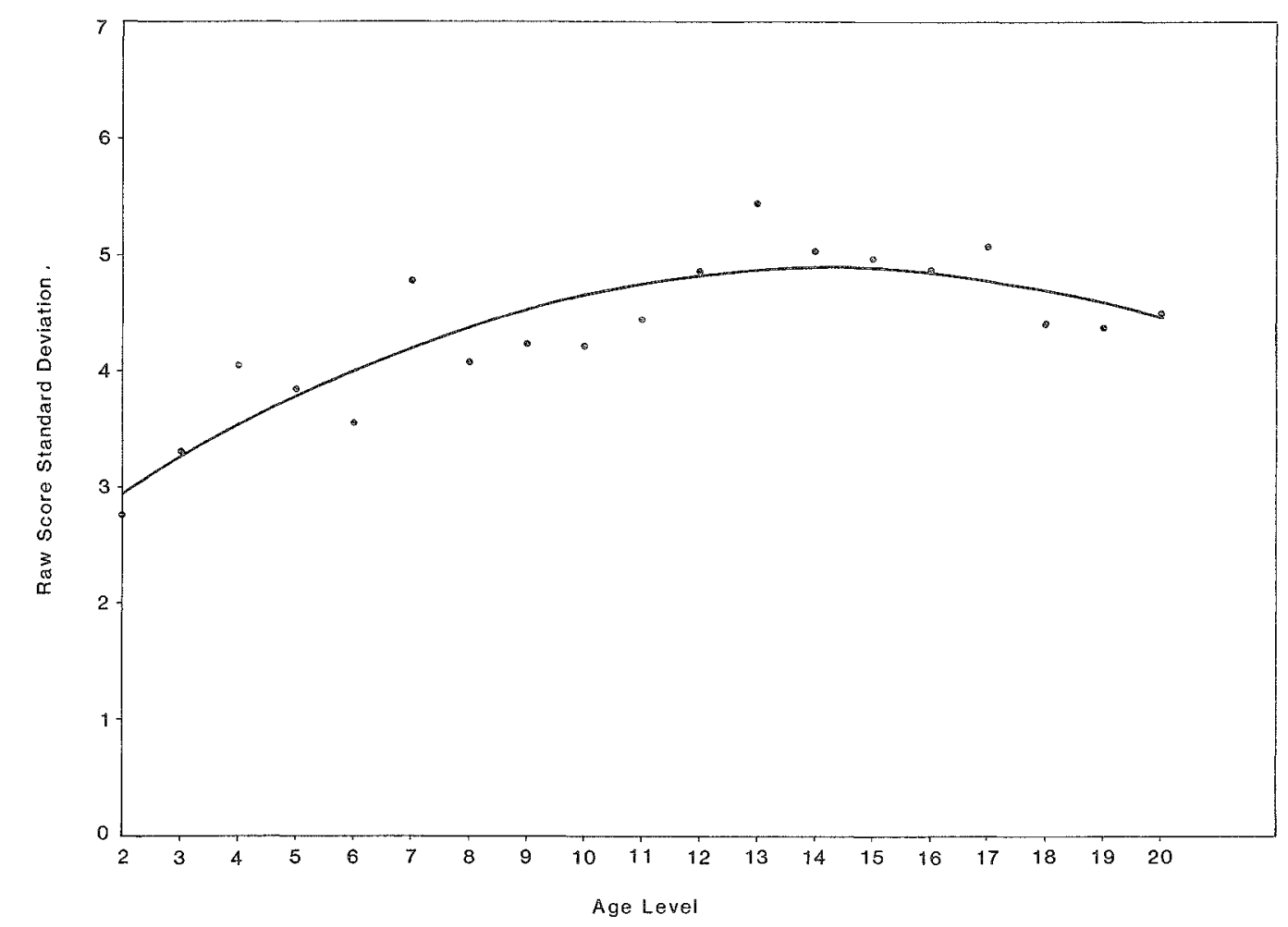

$\frac{y_{a}-\mathbf{M}_{y_{a}}}{\mathrm{~s}_{y_{a}}}=\frac{\tilde{y}_{a}-\mathbf{M}_{\bar{y}_{a}}}{\mathbf{S}_{\tilde{y}_{a}}}$.

The conversion equation resulting from these calculations was found to be

$y_{a}=.94_{\bar{y}_{a}}+.69$.

"Aggregate distribution" raw scores corresponding to "fitted" raw scores of $0.0,1.0,2.0,3.0$, $\ldots, 32.0$ (as in the KABC data) are shown in column 2 of Table 4. The midpercentile ranks in the aggregate distribution, now expressed in terms of the fitted raw scores, are read from the smoothed aggregate ogive (Figure 1). The aggregate distribution is normalized, and scores are assigned a predetermined standard-score mean and standard deviation (100 and 15, respectively, in this illustration). The process of normalization may be accomplished following the procedure outlined in Angoff (1984, pp. 11-15). The columns of Ta- ble 4 also reflect this process, the result of which is a system of normalized standard scores linked at this point to the performance of anchor age children, and expressed on a scale with a mean of 100 and standard deviation of 15 . The adequacy of the normalization may be checked by plotting the standard scores on the scale with a mean of 100 and SD of 15 against their midpercentiles. Such a plot, made on arithmetic probability paper, should be perfectly linear.

For later reference, the fitted anchor age raw scores are plotted on ordinary arithmetic paper against their corresponding standard scores (Column 1 vs. Column 5, in Table 4). A smooth curve is drawn through the points, as in Figure 4, and extrapolated to standard scores 50 and 150 , if possible.

The above steps describe the development of normalized standard scores corresponding to raw 


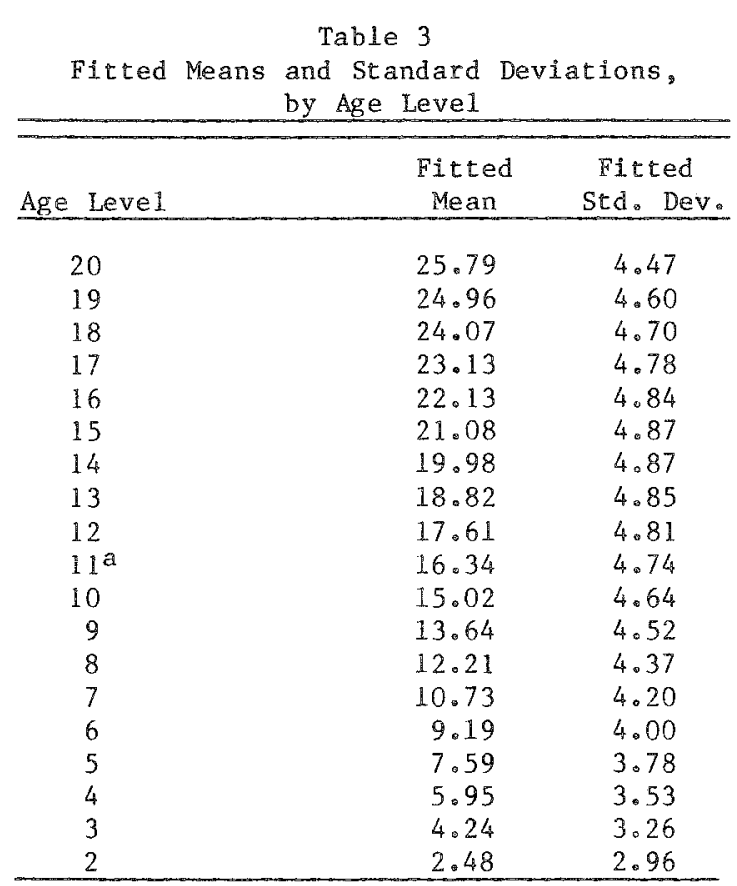

anchor age level

scores at the selected anchor age. The next steps describe the process of developing standard scores for each of the other age levels for which the test is designed and standardized.

1. Using the fitted mean and standard deviation at each age level (see Table 3), calculate the linear parameters of the equation,

$\tilde{y}_{a}=A_{i} y_{i}+B_{i}$,

for converting scores at each age level to scores at the anchor age level, in which

$A_{i}=\mathrm{s}_{\bar{y}_{a}} / \mathrm{s}_{\bar{y}_{i}}$

and

$B_{i}=\mathrm{M}_{\bar{y}_{a}}-A_{i} \mathbf{M}_{\bar{y}_{i}}$,

where $\mathbb{M}_{\bar{y}_{a}}$ and $s_{\bar{y}_{a}}$ are the fitted mean and standard deviation of raw scores at the anchor age level, and $M_{\bar{y}_{i}}$ and $s_{\bar{y}_{i}}$ are the fitted mean and standard deviation of raw scores at any other age level. (Note that all of these fitted values for the KABC data have already been calculated above, and are listed in Table 3.) The values of $A_{i}$ and $B_{i}$ for the $\mathrm{KABC}$ data, calculated from
Equations 8 and 9 , are listed in Table 5.

2. Using the foregoing equations, one for each age level, calculate the "equivalent fitted" anchor age raw scores corresponding to each age level. These equivalent fitted raw scores for the KABC data are shown in Table 6.

3. Enter the equivalent fitted anchor age raw scores in the plot of anchor age raw scores versus standard scores (constructed above and shown in Figure 4), and read the equivalent standard score for each raw score at each age level. The table of raw versus standard scores developed here is the final product of the standardization process, to be used to find the standard score for a child appropriate to his or her age level and performance on the test. For the KABC data, the corresponding table is Table 7.

To the extent that the sampling at each age level has been appropriately representative-which also means that it has reffected the same cohort, differing only in chronological age-the distribution of standard scores for the population should be normal at every age, with a mean of 100 and standard deviation of 15 . An examination of any row of numbers in Table 7 will show, as it should, a set of standard scores progressively declining with age, indicating that a given level of performance is less demanding for an older child than for a younger child and is therefore deserving, as it were, of a lower standard score. Mllustrative of this observation are the values of standard score in the row of numbers corresponding to a raw score of 11. Performance at this level gives a child a standard score of 141 at Age Level 2, 79 at Age Level 12, and only 52 at Age Level 19. It is also observed that, with few exceptions, the decrements in standard scores progressively decrease in size when moving from the younger to the older age levels. This declining progression reflects the declining differences in performance from one age to the next from childhood to adolescence, and is clearly visible in the trace of mean scores in Figure $\mathbb{1}$.

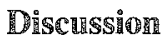

The procedure described in this paper is intended to overcome the deficiencies observed by devel- 
Table 4

Normalization of Aggregate Distribution at the Anchor Age Level (11) and Determination of Standard Scores

\begin{tabular}{|c|c|c|c|c|}
\hline $\begin{array}{l}\text { "Fitted" } \\
\text { Anchor Age (11) } \\
\text { Raw Scores } \\
\end{array}$ & $\begin{array}{l}\text { Equivalent } \\
\text { "Aggregate } \\
\text { Distribution" } \\
\text { Raw Scores } \\
\text { at Achor Age }\end{array}$ & $\begin{array}{c}\text { Smoothed } \\
\text { Mid- } \\
\text { Percentile } \\
\text { Rank }^{2} \\
\end{array}$ & $\begin{array}{c}\text { Norma } 1 \\
\text { Deviace } \\
(z)\end{array}$ & $\begin{array}{c}\text { Standard } \\
\text { Score } \\
(15 z+100) \\
\end{array}$ \\
\hline $\begin{array}{l}32.0 \\
31.0\end{array}$ & $\begin{array}{l}30.7 \\
29.8\end{array}$ & $\begin{array}{l}99.94 \\
99.86\end{array}$ & $\begin{array}{l}3.22 \\
2.99\end{array}$ & $\begin{array}{l}148.3 \\
144.8\end{array}$ \\
\hline $\begin{array}{l}30.0 \\
29.0 \\
28.0 \\
27.0 \\
26.0\end{array}$ & $\begin{array}{l}28.9 \\
27.9 \\
27.0 \\
26.0 \\
25.1\end{array}$ & $\begin{array}{l}99.72 \\
99.42 \\
99.0 \\
98.2 \\
97.2\end{array}$ & $\begin{array}{l}2.77 \\
2.52 \\
2.33 \\
2.10 \\
1.91\end{array}$ & $\begin{array}{l}141.6 \\
137.9 \\
134.9 \\
131.5 \\
128.7\end{array}$ \\
\hline $\begin{array}{l}25.0 \\
24.0 \\
23.0 \\
22.0 \\
21.0\end{array}$ & $\begin{array}{l}24 \cdot 2 \\
23 \cdot 2 \\
22 \cdot 3 \\
21 \cdot 3 \\
20 \cdot 4\end{array}$ & $\begin{array}{l}95.7 \\
93.4 \\
91.0 \\
87.5 \\
83.5\end{array}$ & $\begin{array}{l}1.72 \\
1.51 \\
1.34 \\
1.15 \\
0.97\end{array}$ & $\begin{array}{l}125.8 \\
122 \cdot 6 \\
120 \cdot 1 \\
117.3 \\
114.6\end{array}$ \\
\hline $\begin{array}{l}20.0 \\
19.0 \\
18.0 \\
17.0 \\
16.0\end{array}$ & $\begin{array}{l}19.5 \\
18.5 \\
17.6 \\
16.6 \\
15.7\end{array}$ & $\begin{array}{l}78.4 \\
72.0 \\
65.0 \\
57.2 \\
48.2\end{array}$ & $\begin{array}{r}0.79 \\
0.58 \\
0.39 \\
0.18 \\
-0.05\end{array}$ & $\begin{array}{r}111.8 \\
108.7 \\
105.8 \\
102.7 \\
99.3\end{array}$ \\
\hline $\begin{array}{l}15.0 \\
14.0 \\
13.0 \\
12.0 \\
11.0\end{array}$ & $\begin{array}{l}14.8 \\
13.8 \\
12.9 \\
12.0 \\
11.0\end{array}$ & $\begin{array}{l}40.0 \\
31.0 \\
23.5 \\
17.7 \\
12.0\end{array}$ & $\begin{array}{l}-0.25 \\
-0.50 \\
=0.72 \\
=0.93 \\
-1.18\end{array}$ & $\begin{array}{l}96.2 \\
92.6 \\
89.2 \\
86.1 \\
82.4\end{array}$ \\
\hline $\begin{array}{r}10.0 \\
9.0 \\
8.0 \\
7.0 \\
6.0\end{array}$ & $\begin{array}{r}10.1 \\
9.1 \\
8.2 \\
7.3 \\
6.3\end{array}$ & $\begin{array}{l}8.5 \\
5.5 \\
3.6 \\
2.2 \\
1.2\end{array}$ & $\begin{array}{l}-1.37 \\
-1.60 \\
-1.80 \\
-2.01 \\
-2.26\end{array}$ & $\begin{array}{l}79.4 \\
76.0 \\
73.0 \\
69.8 \\
66.1\end{array}$ \\
\hline $\begin{array}{l}5.0 \\
4.0 \\
3.0 \\
2.0\end{array}$ & $\begin{array}{l}5.4 \\
4.4 \\
3.5 \\
2.6\end{array}$ & $\begin{array}{l}0.65 \\
0.35 \\
0.15 \\
0.04\end{array}$ & $\begin{array}{l}-2.48 \\
-2.70 \\
-2.97 \\
-3.39\end{array}$ & $\begin{array}{l}62.7 \\
59.5 \\
55.5 \\
49.1\end{array}$ \\
\hline
\end{tabular}

aread from Figure 1 .

borresponding to Smoothed Midpercentile Ranks (third column)。 
Figure 4

Plot of Fitted Anchor Age Scores Versus Standard Scores

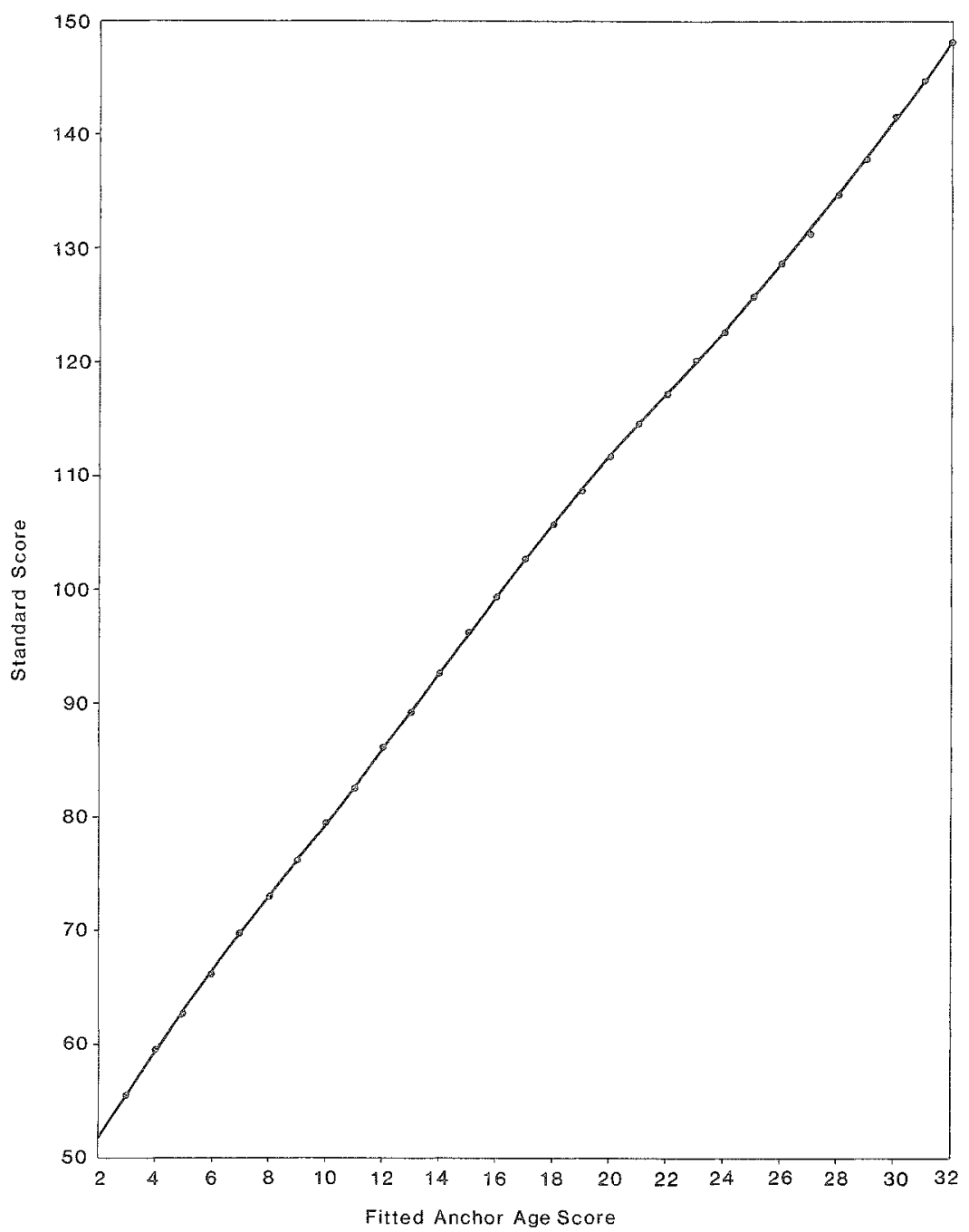

opers of tests that are meant to be age-articulated, in which the number of individuals used for standardization at each age level is necessarily small. The philosophy underlying the procedure is that the expected (and observed) trend in score means during early childhood may be used to guide the aggregation of scores across all levels. The advantages of the procedure are several:

1. The data developed here are more stable than the observed raw data at each age, inasmuch as they represent a composite of all data, aggregated over all age levels; following appropriate adjustments for trends, the data gain strength by force of sheer numbers. Any further irregularities remaining in the aggregated distribution are then smoothed out and normalized.

2. The resulting distributions at each age level 
Table 5

Slope $\left(A_{i}\right)$ and Intercept $\left(B_{i}\right)$ Values for Converting Raw Scores at Each Age Level to Raw Scores at the Anchor Age to Yield Fitced Values of Mean and Standard Deviation ${ }^{2}$

\begin{tabular}{ccr}
\hline Age Leve1 & $A_{i}$ & \multicolumn{1}{c}{$B_{i}$} \\
\hline 20 & 1.06 & -11.01 \\
19 & 1.03 & -9.37 \\
18 & 1.01 & -7.90 \\
17 & 0.99 & -6.56 \\
16 & 0.98 & -5.33 \\
15 & 0.97 & -4.17 \\
14 & 0.97 & -3.08 \\
13 & 0.98 & -2.03 \\
12 & 0.99 & -1.01 \\
$11 b$ & 1.00 & 0.00 \\
10 & 1.02 & 1.01 \\
9 & 1.05 & 2.04 \\
8 & 1.08 & 3.11 \\
7 & 1.13 & 4.25 \\
6 & 1.18 & 5.47 \\
5 & 1.25 & 6.83 \\
4 & 1.34 & 8.37 \\
3 & 1.45 & 10.18 \\
2 & 1.60 & 12.37 \\
\hline
\end{tabular}

aitted by the application of second degree equations to the traces of observed means and standard deviations.

bAnchor age level.

are far more comparable with one another than are the observed raw data because they do, in fact, represent the same set of observations, except for the adjustments in mean and standard deviations, made in accordance with the pattern of growth changes through the succession of age levels.

3. These adjustments have been made in accordance with the trends in means and standard deviations, smoothed out in order to avoid the irrelevant components of the variation from age to age and in order to represent only the lawful, orderly progression from age to age.
This is done by centering each distribution, in effect, on the smooth growth curve. The actual procedure followed in this standardization yields only one final distribution of standard scores, which is applicable to children at all ages through the use of the conversions from raw to standard score. Put another way, it yields only one set of percentile ranks, available in any table of the normal curve. They attach directly to the standard scores and are interpretable at any age for which the test is appropriate.

As already indicated, the assumptions made in this procedure are that the sampling of children at each age level has been conducted in such a way as to represent the same cohort at every age level, that the smooth trends drawn in Figures 1 and 2 result from expected changes in children as a function of normal intellectual growth, and that all irregularities in the trends are attributable to random fluctuations. The representation of the same data at every age, with adjustments for these age changes, thus should more closely approximate the kinds of outcomes that might have been observed had a longitudinal, rather than cross-sectional, norming program been undertaken in the standardization process.

\section{ReVterenges}

Angoff, W. H. (1984). Scales, norms, and equivalent scores. Princeton NI: Educational Testing Service. [Also in R. L. Thorndike (Ed.) (1971). Educational measurement (pp. 508-600). Washington DC: American Council on Education.]

Kaufmañ, A. S., \& Kaufman, N. L. (1983). Kaufman Assessment Battery for Children. Circle Pines MN: American Guidance Service.

McCarthy, D. (1972). McCarthy Scales of Children's Abilities. New York: The Psychological Corporation.

Peters, C. C., \& Van Voorhis, W. R. (1940). Statistical procedures and their mathematical bases. New York: McGraw-Hill.

Terman, L. M., \& Merrill, M. A. (1937). Measuring intelligence. New York: Houghton Miffin.

Thorndike, R. L. (1973). Stanford-Binet Intelligence Scales; 1972 norms tables. Boston: Houghton Mifflin. 


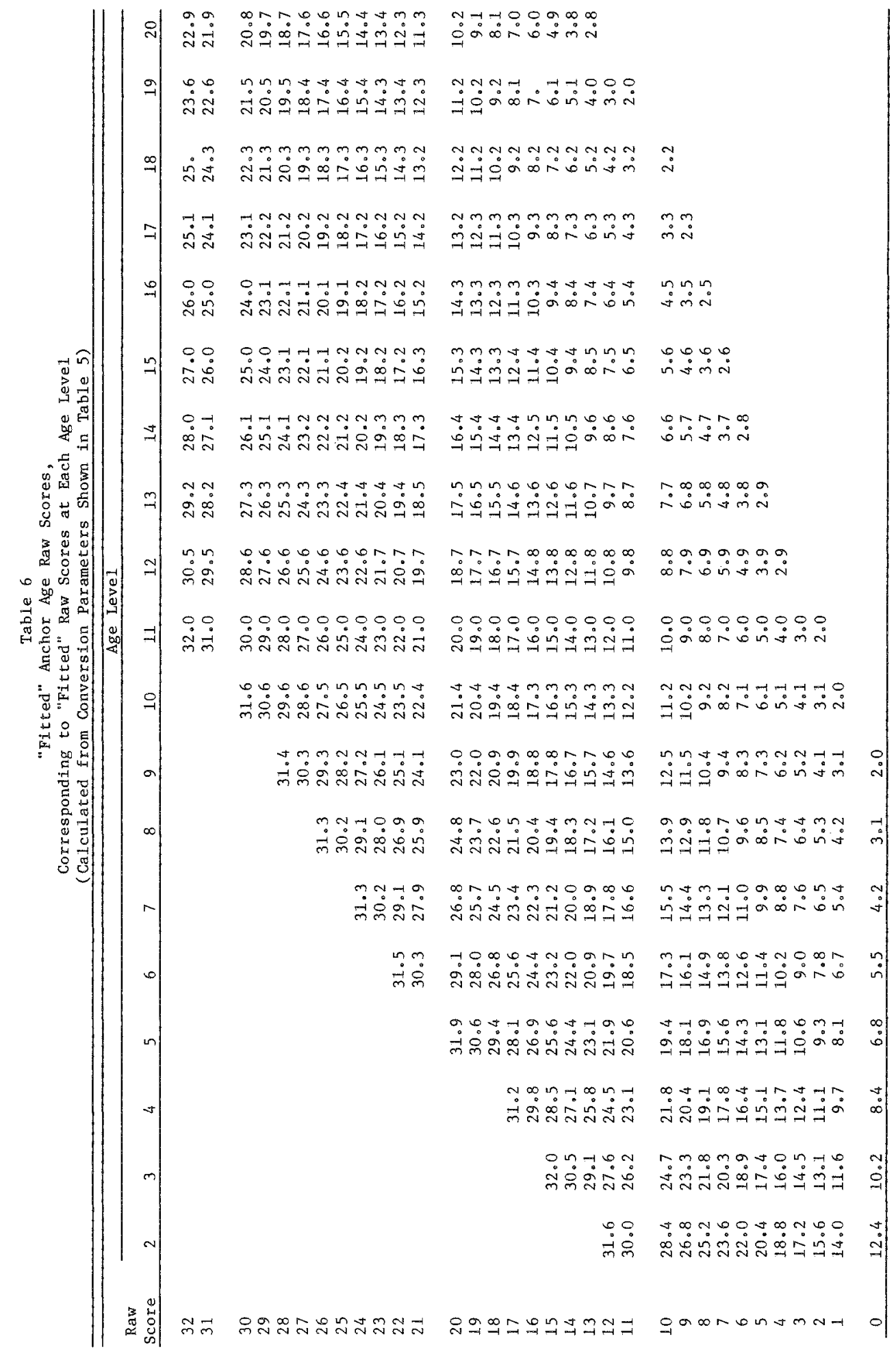

Downloaded from the Digital Conservancy at the University of Minnesota, http://purl.umn.edu/93227. May be reproduced with no cost by students and faculty for academic use. Non-academic reproduction requires payment of royalties through the Copyright Clearance Center, http://www.copyright.com/ 


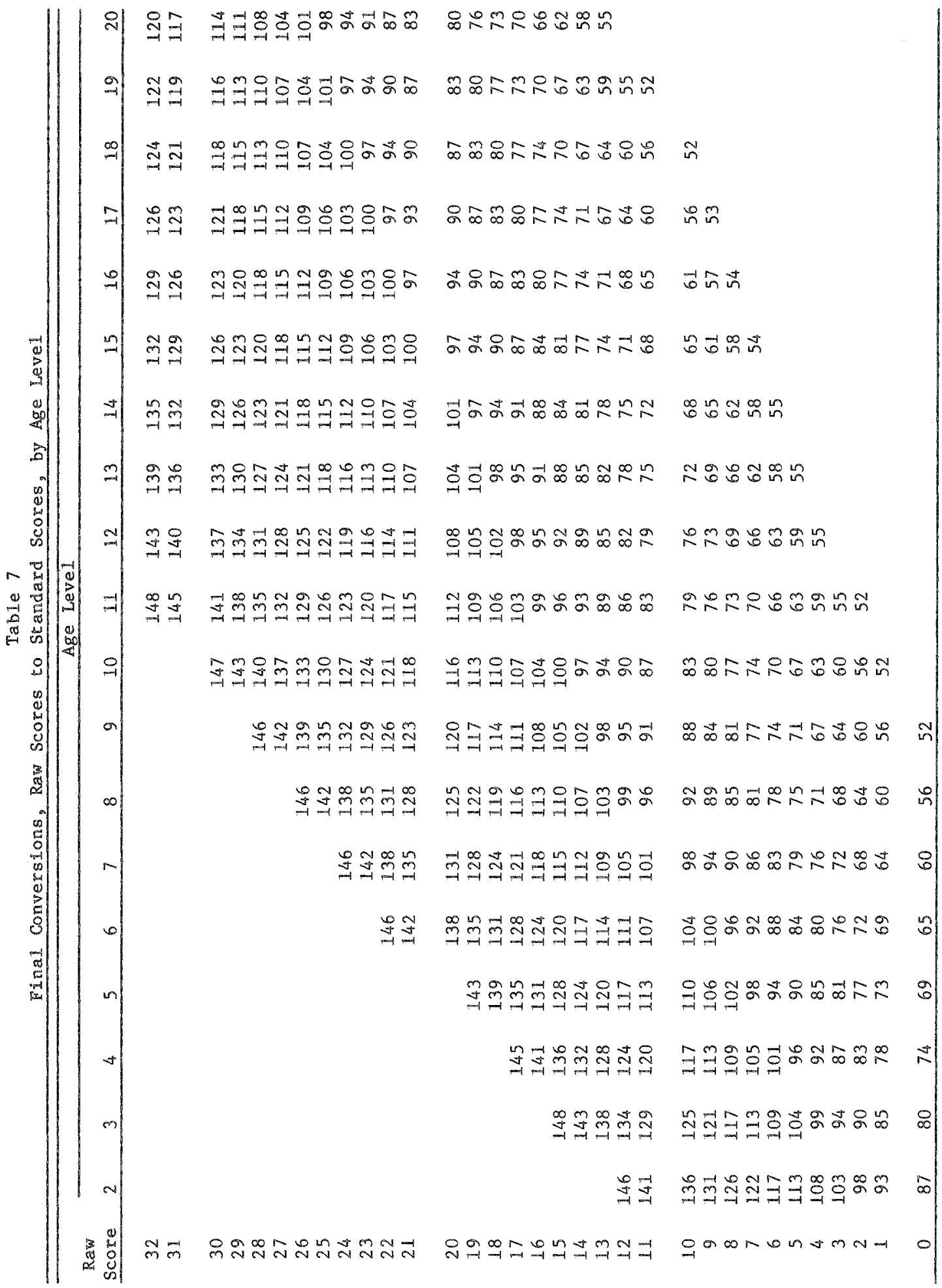

Downloaded from the Digital Conservancy at the University of Minnesota, http://purl.umn.edu/93227. May be reproduced with no cost by students and faculty for academic use. Non-academic reproduction requires payment of royalties through the Copyright Clearance Center, http://www.copyright.com/ 
Wechsler, D. (1974). Wechsler Intelligence Scale for Children-Revised. New York: The Psychological Corporation.

\section{Author's Address}

Send requests for reprints or further information to William $H$. Angoff, Educational Testing Service, Princeton NJ 08541, U.S.A.

Downloaded from the Digital Conservancy at the University of Minnesota, http://purl.umn.edu/93227. 